Auster, $\mathrm{n}^{\mathrm{o}}$ 22, e036, 2017. ISSN 2346-8890

Universidad Nacional de La Plata.

Facultad de Humanidades y Ciencias de la Educación

Centro de Estudios Latinos

\title{
Cipo y la monarquía en Metamorfosis de Ovidio ${ }^{1}$
}

\section{Introducción y marco teórico}

En el presente trabajo analizaremos la representación de la monarquía en el episodio de Cipo del libro XV de Metamorfosis de Ovidio. Sostendremos que, si bien en la época del poeta la figura del rey era negativa y estaba asociada a la idea de tiranía, se puede ver a partir de elementos que señalaremos oportunamente un cambio en la mirada sobre este tipo de gobierno que se relaciona con los cambios sociales que se estaban viviendo en la época. Para realizar este análisis nos serviremos del concepto de estructura del sentir de Raymond Williams, ya que postulamos que esta nueva visión no está dada de manera explícita sino que más bien el texto señala un conflicto, una crisis, una grieta entre un idea dominante, la visión negativa de la figura del rey, y un nuevo sentimiento.

Williams define la estructura del sentir como la expresión de la interacción entre el "carácter social dominante de un período" y la "experiencia real”. Esta interacción denota un conflicto, una rivalidad, un enfrentamiento.

[El arte] crea, mediante nuevas percepciones y respuestas, elementos que la sociedad, como tal, no es capaz de realizar [...] encontramos una descripción, una discusión, una exposición por medio de la trama y una vivencia del carácter social. También hallamos, en ciertas formas y dispositivos característicos, pruebas de los atascos y problemas no resueltos de la sociedad: a menudo presentes por primera vez en la conciencia de este modo [...] parte del arte expresa sentimientos que la sociedad, en su carácter general, no podía expresar. Estos pueden ser las respuestas creativas que sacan a la luz nuevos sentimientos. Pueden ser

1 Una versión previa de este trabajo fue presentada en las VII Jornadas de Estudios Clásicos y Medievales "Diálogos culturales". Las citas de Metamorfosis provienen de Tarrant, R. J., P. Ovidi Nasonis Metamorphoses, Oxford, 2004.

Cita sugerida: Mollo Brisco, M. E. (2017). Cipo y la monarquía en Metamorfosis de Ovidio. Auster, (22), e036. Recuperado de: http://doi.org/10.24215/23468890e36

Esta obra está bajo licencia Creative Commons Atribución-NoComercial-CompartirIgual 4.0 Internacional http://creativecommons.org/licenses/by-nc-sa/4.0/deed.es_AR 
también la mera constancia de las omisiones: la reparación o el intento de reparación de necesidades humanas insatisfechas ${ }^{2}$.

Este concepto es utilizado para "describir algo que sucede específicamente en las obras de arte, en la literatura: que se comunica y se realiza en un nivel diferente al de ideología"33. Esto nos parece especialmente importante para el análisis de las obras del período augustal ya que evita la visión de los textos como propaganda política que desestima que la obra literaria es un discurso diferente y trabaja con otros materiales. El concepto de Williams mantiene la idea de la especificidad de la literatura, que radica justamente en la idea de "específica organización del sentimiento".

\section{Contexto histórico de Metamorfosis}

Para intentar conocer, por lo menos a grandes rasgos, el carácter dominante de la época tendremos que ubicar la obra en su contexto histórico. Metamorfosis fue escrita entre el 2 y el 8 d. C. durante el principado de Augusto. Este período fue, desde el punto de vista político y social, una etapa de transición. Augusto se esforzaba por asegurar que él había restaurado la res publica luego de décadas de guerras civiles e inestabilidad política pero estaba claro que esta forma de gobierno ya no existía como tal. La figura de un gobernante único era muy fuerte. Galinsky señala:

Even if gradual, it must have been clear to Augustus' contemporaries that important changes were taking place. There was no sudden jump from republic to monarchy, but there was a republican system with a princeps [...] the Augustan principate emerged as "the binding link between Republic and Empire". 5

2 Williams, R., La larga revolución, Buenos Aires, Nueva Visión, 2003, 75-76.

3 Sarlo, B., "Raymond Williams y Richard Hoggart: sobre cultura y sociedad", Punto de vista, II, 6, julio 1979, 9-18, 13.

4 Sarlo, Punto de Vista, 14

5 Galinsky, K., "Introduction. The Augustan Evolution", en: Augustan Culture. An Interpretive Introduction, Princeton, Princeton University P., 1996, 3-9, 9. 
Como señala Galinsky, el funcionamiento de la "constitución" republicana se basaba más en las tradiciones que en los aspectos legales. Y Augusto aprovechó este hecho y basó su legitimidad en una vuelta a esos valores y principios básicos. Mantuvo el consulado con sus funciones intactas pero ocupó ese cargo todos los años después del 31 a. C. y el cónsul que lo acompañaba en sus funciones le era adicto. Es decir, el poder recaía en su persona pero se mantenía la fachada del consulado. Debido a que el título de rey se cargó de una valoración negativa luego del derrocamiento de Tarquino el Soberbio, no podía volver a ser utilizado. En el año 27 a. C. Augusto anuncia que la paz estaba restaurada y que ponía el poder a disposición del Pueblo y el Senado romanos. Pero, como señala Grimal, Octavio había adquirido mucha influencia en Roma y no podía volver a ser un simple ciudadano.

Era precisamente esa posición excepcional lo que se trataba de expresar con un título, con un nombre nuevo. En un momento dado los senadores pensaron en concederle el de Rómulo [...] Rómulo había fundado la ciudad, es cierto, pero fue rey [...] a pesar de su prestigio, el nombre era de mal agüero y resultaba imposible pretender que la República estaba restaurada y a la vez conferir, aun indirectamente, honores reales al hombre de quien había dependido esa restauración. ${ }^{6}$

En su lugar, se le ofreció el nombre Augusto ${ }^{7}$, que evocaba la idea del favor de los dioses y la misión divina de su empresa y evitaba el problema de la connotación negativa ligada a la monarquía. Este nombre vino a ocupar un vacío, un espacio "sin nombre".

\section{Metamorfosis}

Analizaremos ahora cómo aparece la figura del rey en los pasajes referidos a Rómulo, Numa y Cipo en Metamorfosis de Ovidio.

En el libro XIV el poema alcanza el "período histórico". El punto que marca la división entre el mito y la historia es la guerra de Troya. ${ }^{8}$ Se narra la llegada de Eneas al

6 Grimal, P., El siglo de Augusto, Buenos Aires, Eudeba, 1965, 8.

7 Grimal, El siglo de Augusto, 8: "El vocablo no era nuevo, lo aplicaban ordinariamente a lugares u objetos consagrados, designados por los augures."

8 Cf. Myers, S. (ed.), Ovid. Metamorphoses. Book XIV, Cambridge, Cambridge University Press, 2009. 
Lacio, luego la lista de reyes de Alba y la fundación de Roma. El libro termina con las apoteosis de Rómulo y Hersilia. El libro XV, que se enlaza con el anterior a partir del problema de la sucesión al trono, comienza con el reinado de Numa.

Del período histórico correspondiente a la monarquía sólo se mencionan dos reyes, Rómulo y Numa, y ambos están caracterizados de manera positiva, según veremos a continuación. Rómulo representa a un gobernante al principio guerrero pero luego pacificador y dador de leyes; Numa, a un gobernante ligado a la paz y a la religión.

El tratamiento de los hechos referidos a Rómulo es bastante abreviado. Principalmente se destacan dos hechos, su participación en la guerra contra los sabinos, donde se pone el énfasis en la transformación de una fuente, y su apoteosis. Queremos destacar en primer lugar que en la caracterización de Rómulo se omiten los hechos que pueden resultar negativos. Por un lado, se excluye la muerte de Remo y la posible visión negativa del fratricidio ${ }^{9} \mathrm{y}$, además, se menciona la guerra con los sabinos sin explicitar las causas, el rapto de las sabinas; simplemente se nombra a los patres Sabini. Rómulo se destaca por su iniciativa en la guerra, quae postquam Romulus ultro/ obtulit (Met XIV, 799800). La paz entre los pueblos finalmente es decidida por ambas partes- no se menciona la intervención de las mujeres sabinas como en otras versiones ${ }^{10}$ - y los generales de cada lado gobiernan en conjunto ${ }^{11}$. A continuación se dice que luego de morir Tacio, Rómulo se encontraba dictando leyes igualitarias a los sabinos y a los romanos: Occiderat Tatius, populisque aequata duobus,/ Romule, iura dabas (Met. XIV, 805-806). El adjetivo aequata

9 La primera referencia a Rómulo es en singular (nepotis); se omite el rol de Remo en la tradición (Myers, S., Ovid. Metamorphoses. Book XIV, 194)

10 Liv., I, 13; Dion. Hal., II 45-46; Plut., Rom., XIX.

11 Sobre este punto nos parece convincente la argumentación de Wheeler, S., Narrative Dynamics in Ovid's Metamorphoses, Tübingen, 2000, 113, que responde a las críticas sobre el acotado espacio que dedica Ovidio a la fundación de Roma: "In light of closural dynamics already set in motion by Pomona and Vertumnus, it makes narratological sense that Ovid passes over the beginnings of Rome. His narrative focus has shifted to endings. Thus, he passes over the beginning and middle of Romulus's career and concentrates on this role of conclusion of the civil war with the Sabines (14.775-804), which is repetition of the war fought between the Trojans and Italians (14. 450-588)". 
puede interpretarse como una refutación a la tradición que mostraba a Rómulo como un tirano, razón por la cual había sido asesinado por los senadores ${ }^{12}$.

El otro hecho importante es la apoteosis de Rómulo. Sobre su muerte había una versión según la cual Rómulo había sido asesinado por los senadores o por el pueblo a causa de su despotismo ${ }^{13}$. En Metamorfosis se narra la otra versión según la cual este rey fue convertido en el dios Quirino a pedido de su padre Marte. Además de su ascendencia divina se destaca como motivo de su deificación su virtus: fundamine magno/ res Romana valet (Met. XIV, 808-809); tanto [...] regi (Met. XV, 2). La grandeza del pueblo romano está garantizada por sus fuertes cimientos.

En el momento en que Rómulo es llevado al cielo se dice que se encontraba impartiendo leyes no reales: reddentemque suo non regia iura Quiriti/ abstulit Iliaden (Met. XIV, 823-824). En estos versos podemos observar la tensión que mencionábamos en la introducción entre el modelo social, connotación negativa de la monarquía, y la experiencia real. Rómulo, el rey fundador de Roma, el gobernante pacificador y legislador, que prefigura a Augusto, no actúa como tal. No vemos en esto una crítica a la monarquía sino la muestra de un malestar, una incomodidad entre lo que "se siente", que Rómulo gobernaba de manera justa, y lo que "se debe sentir", que un rey era un tirano. Este conflicto no se expresa de manera explícita sino que se interpreta como un "sentir" a través de los elementos mencionados.

Numa, de origen sabino, es el sucesor de Rómulo. Debido a su afán de conocimiento (animo maiora capaci/concipit et, quae sit rerum natura, requirit, Met. XV, 5-6) viaja a Crotona, donde aprende la doctrina pitagórica. A su regreso es nombrado rey a pedido de los ciudadanos (ferunt ultroque petitum/accepisse Numam populi Latialis habenas, Met. XV, 480-481). Está casado con la ninfa Egeria y las Camenas son sus guías (coniuge qui felix nympha ducibusque Camenis, Met. XV, 482). A diferencia de Rómulo, que es un rey más caracterizado por su aspecto guerrero (gentem feroci/ adsuetam bello, Met. XV, 483-484), el reinado de Numa se caracteriza por sus acciones religiosasenseñanza de los sacrificios- y su acción pacificadora -transmisión del hábito de la paz.

12 Cf. Myers, S. (ed.), Ovid. Metamorphoses. Book XIV, p.203

13 En Fasti se menciona la versión del asesinato pero se la rechaza (II, 496-498). 
La imagen de Numa representada en la obra es positiva. Como señala Martínez Astorino, si bien Numa no tiene ascendencia divina y no recibe la apoteosis, luego de su muerte es llorado por todos los romanos, acción que no es mencionada con tanto énfasis en las fuentes, lo cual es señal de que era un hombre excepcional ${ }^{14}$. Además hay una asociación entre su reinado y la edad de oro descripta por Pitágoras ${ }^{15}$. Por último, hay una alusión a Augusto, no sólo en el verbo succedere que aparece al principio del libro, sino fundamentalmente en el motivo de la pax:

Las enseñanzas de Pitágoras sobre la paz de la edad de oro le permiten a Numa, que no es philosophus sino rex, consolidar la paz en la edad de hierro de la historia de Roma que en ese momento se encontraba en sus orígenes. La pax de Augusto remeda esa imagen de la edad de oro $[\ldots]$ pero agrega el elemento de la guerra como condición necesaria. Intratextualmente, Numa no constituye una evasión, sino un eslabón del desarrollo de una historia que, para el caso de Metamorfosis, termina políticamente con Augusto. La identificación con Pitágoras y con Augusto y el empleo de la palabra pax conforman así una cadena de sentido. ${ }^{16}$

Es interesante que luego de Rómulo y Numa no se menciona a ningún otro rey. El llanto de Egeria por la muerte de su esposo permite introducir el relato de Hipólito quien comparte sus desgracias con ella y relata su transformación en Virbio. Egeria sin embargo no encuentra consuelo en esta historia y es transformada en fuente por Diana. El asombro que esta transformación genera en Hipólito es similar al producido por las tres metamorfosis que se narran a continuación: la de Tages, la del hasta Romuli y la de Cipo. Estas historias además están conectadas porque las tres son relatos etiológicos. Las dos primeras historias son más breves y, como señala Marks, no se les ha prestado mucha atención ${ }^{17}$. Compartimos con este autor la idea que las dos primeras narraciones son

14 Martínez Astorino, P., "Numa y la construcción poética de la historia en las Metamorfosis de Ovidio". QUCC $102(131) / 3,2012,149-164,154-156$.

15 Martínez Astorino, "Numa y la construcción poética”, 156-158.

16 Martínez Astorino, "Numa y la construcción poética”, 161.

17 Marks, R., "Of Kings, Crowns, and Boundary Stones: Cipus and the hasta Romuli in Metamorphoses 15", TAPhA 134, 2004 197-131, 107-108. 
relevantes para una interpretación de la historia de Cipo en relación con la idea de la monarquía y la importancia de la misión divina del rey.

La primera historia ocupa siete versos y en ella se narra la transformación de un terrón de tierra en un hombre al que los etruscos llamaron Tages y fue el primero que enseñó a este pueblo a descubrir los sucesos futuros.

La segunda historia es desarrollada en solo cinco versos y relata la transformación en árbol de una lanza que, al ser arrojada por Rómulo, quedó clavada en el monte Aventino.

La historia de Cipo es más largo, ocupa veintinueve versos. Cipo, que llegaba a Roma como victor, ve su reflejo en un río y nota que le han crecido unos cuernos en su cabeza. Un arúspice etrusco consulta las entrañas de unas ovejas sacrificadas y augura grandes empresas para él aunque aún no manifiestas. Al levantar los ojos ve los cuernos y vaticina que si es recibido en la ciudad cumplirá su destino de convertirse en rey. Cipo retrocede y señala que preferiría vivir en el exilio. Sin embargo, en lugar de marcharse tapa sus cuernos con laurel y convoca al pueblo y al Senado. Les revela que hay uno con cuernos en su frente que se convertirá en rey y dará leyes de esclavitud si se le permite la entrada en la ciudad. Les ordena que a éste lo exilien, lo encadenen o lo maten. Ante la intriga de los oyentes revela sus cuernos y el pueblo y el Senado, no queriendo que quedase sin honor, lo ciñen con una corona festiva, le dan una porción de tierra y por último esculpen sus cuernos en una de las puertas de Roma.

Este episodio ha sido leído en clave antiaugustea ${ }^{18}$, como una muestra de la herencia monárquica inevitable ${ }^{19}$ y también como una alusión a Agripa $^{20}$. Nosotros daremos una lectura del episodio bajo la luz del concepto de estructura del sentir mencionado en la introducción, es decir, como una muestra del cambio de la experiencia con respecto a esta

18 Galinsky K., "The Cipus Episode in Ovid's Metamorphoses (15.565-621)”, TAPhA, 98, 1967, 181-191. 19 Marks, “ Of Kings, Crowns, and Boundary Stones”.

20 Díez Platas, F. y López Barja de Quiroga, P., "Cipo en las Metamorfosis de Ovidio y en su recepción posterior”, en C. Fornis- J. Gallego- P. López Barja -M. Valdés (eds.), Dialéctica histórica y compromiso social. Homenaje a Domingo Plácido, Zaragoza, 2010, 275-306. 
forma de gobierno. Como ha señalado Martínez Astorino ${ }^{21}$ en un trabajo reciente, la monarquía se ve como una opción viable. Y es viable cuando el reinado es asumido por seres excepcionales, como Rómulo, Numa, Cipo (potencialmente ya que su reinado no llega a desarrollarse), Julio César y Augusto ${ }^{22}$.

En el episodio de Cipo podemos ver la tensión entre un modelo social articulado y la experiencia real, vemos allí una "estructura del sentir". Por un lado Cipo, republicano, no puede concebir la idea de ser rey porque pertenece a un carácter social anterior, según el cual ser rey era ser un tirano (quem vobis indicat augur/si Romam intrarit, famularia iura daturum., Met. XV, 496-497) pero el texto nos muestra indicios de un conflicto con respecto a ese modo de sentir anterior. Por un lado se hace énfasis en que el reinado de Cipo está predicho por los dioses (sic fata iubent v. 584, fatalis [...] tyranni v. 602). ${ }^{23} \mathrm{El}$ peso de los hados nos parece fundamental, no sólo por la referencia al fatum de Eneas ${ }^{24}$ sino

21 Martínez Astorino, P. “Cipo-César en las Metamorfosis de Ovidio: ¿una reivindicación de la monarquía?”, Euphrosyne 45, 2017, 268.

22 Coincidimos con Marks, "Kings, Crowns, and Boundary Stones", en que el episodio de Cipo debe leerse en conexión con los de los reyes Rómulo y Numa. La historia de la ciudad de Roma comienza con sus dos primeros reyes, Rómulo y Numa, pero luego el texto pasa de largo todos los otros reyes para llegar hasta la historia de Cipo en algún momento de la temprana República. Además, como señala este autor, Rómulo es recordado por el episodio del hasta Romuli.

23 Guillaumin, J-Y., (“Les cornes de Cipus”, en : F. Galtier- Y. Perrin, (eds.), Ars pictoris, ars scriptoris. Peinture, littérature, histoire. Mélanges offerts à Jean-Michel Croisille, Clermont-Ferrand, 2008, 165-171) señala que en Valerio Máximo el episodio de Cipo está ejemplificando la pietas hacia la patria mientras que en Ovidio se subrayan sus aspiraciones reales. Para nosotros lo que se destaca en este episodio es justamente la tensión entre la pietas hacia la patria y los conciudadanos y la pietas hacia los dioses. Además este episodio en el último libro nos recuerda al episodio de Deucalión y Pirra en el primer libro. Estos últimos personajes son ejemplos de pietas hacia los dioses. Ellos siguen lo designado por los dioses a pesar de su desconfianza inicial. Luego del diluvio y de quedar la pareja como únicos ejemplares humanos, la diosa Temis les revela que deben cubrir su cabeza y arrojar los huesos de la gran madre. Pirra desconfía, teme ultrajar la sombra de su madre. Pero, luego de reflexionar, Deucalión acepta el oráculo: “... 'aut fallax' ait 'est sollertia nobis,/ aut (pia sunt nullumque nefas oracula suadent!)/ magna parens terra est: lapides in corpore terrae/ ossa reor dici; iacere hos post terga iubemur." "O mi inteligencia me es engañosa o (¡los oráculos son piadosos y no recomiendan ningún crimen!)/ la magna madre es la tierra: creo que las piedras son llamadas huesos en el cuerpo de la tierra; se nos ordena que las arrojemos por la espalda" (Met. I, 391-394).

24 La "Eneida ovidiana" ocupa la segunda parte del libro XIII y finaliza bien entrado el libro XIV. Luego de la apoteosis de Eneas, el poema enumera los reyes latinos y la descendencia que termina en Rómulo. Por esto, nos parece apropiada la conexión con el fatum y la pietas de Eneas. Martínez Astorino, "Cipo-César en las Metamorfosis de Ovidio", dice con respecto a la respuesta del arúspice: "Ese es el omen y en él no hay 
porque esta historia está relacionada, como señalamos antes, con la historia de Tages, que es quien enseñó el arte de la adivinación a los etruscos, de quienes aprendieron los romanos. Como señala Marks, también podemos encontrar una relación con la historia del hasta Romuli que según el mito ocurría inmediatamente después de que Rómulo tomara los auspicios. El arúspice que interpreta el prodigio de los cuernos de Cipo es llamado en el verso 596 augur, hecho que puede interpretarse en conexión con la interpretación del vuelo de las aves por Rómulo. Es decir, estas dos historias que preceden a la de Cipo están reforzando la importancia de la adivinación y poniendo en duda la posibilidad de escape de este legado monárquico.

Otro hecho que muestra la vacilación con respecto al destino monárquico es la actitud de Cipo luego de escuchar las palabras del arúspice ya que, a pesar del rechazo inicial de su destino real, no se aleja de la ciudad sino que vuelve al pueblo para escuchar su opinión. Este hecho no aparece en la otra versión de la historia que poseemos, la de Valerio Máximo ${ }^{25}$, según la cual Cipo se exilia ni bien escucha la noticia.

La reacción del pueblo también nos muestra un conflicto entre lo que se debe sentir y "lo que realmente se está viviendo". El pueblo quiere impedir que Cipo muestre sus cuernos y se duele y gime cuando descubre la verdad. Pareciera que el pueblo estuviera experimentando un nuevo tipo de sentir: ¿acaso una persona digna por sus méritos no puede ser rey? El episodio termina con un acto conciliatorio: Cipo, que no puede ser nombrado rey, no puede tampoco quedar sin recompensa. Por eso el pueblo le otorga una corona festiva y el senado le otorga la cantidad de tierra que pudiera abarcar con un arado en un día:

ruris honorati tantum tibi, Cipe, dedere quantum depresso subiectis bobus aratro conplecti posses ad finem lucis ab ortu. (Met. XV, 617-619).

te dieron a ti, Cipo, como recompensa tanto campo

ninguna nota negativa. De hecho, son los hados quienes ordenan su cumplimiento: con rumpe moras se alude a la aparición de Mercurio a Eneas para recordarle su fatum en el libro 4 de la Eneida (569), una obra que tiene al fatum como motivo central."

25 También hay una referencia en Plinio el Viejo pero es muy breve (HN XI, 45, 123). 
cuanto pudieras abarcar con un arado que con bueyes uncidos

recibiera tu peso desde el nacimiento hasta el final del día.

Esta última recompensa asocia a Cipo con Rómulo, ya que recuerda la fundación de Roma que se llevó a cabo a través del trazado de los límites con un arado.

\section{Conclusión}

En los pasajes analizados intentamos mostrar cómo puede verse en el texto una nueva mirada con respecto a la monarquía. Para realizar este análisis tomamos como perspectiva teórica el concepto de Raymond Williams de "estructura del sentir" que nos permite entender esa nueva mirada como una tensión que el texto descubre entre un modelo social anterior, que asociaba la figura del rey con la de un tirano, y un nuevo sentir que aflora en medio de los cambios políticos y sociales que estaban ocurriendo en la época. Se quiso mostrar cómo este conflicto se deja entrever a partir de la selección que realiza el poeta de los personajes que ilustran la "etapa histórica” y su descripción. Este período está signado por la monarquía: figuran los dos primeros reyes, Rómulo y Numa, valorados positivamente, y luego el texto salta al período de la República para mencionar a Cipo, un personaje que está destinado a ser rey. Además se subraya la importancia de la adivinación y el peso de los hados. Este malestar encuentra en el texto una respuesta conciliatoria: la figura de un rey con virtus como Rómulo, como Numa, como Cipo, si hubiera sido rey, y quizás como podría haber sido Julio César y como podría serlo Augusto.

María Eugenia Mollo Brisco Universidad Nacional de La Plata eugeniamollo@gmail.com 


\title{
Resumen:
}

Nuestro propósito en este trabajo es analizar cómo el episodio de Cipo en el libro XV de Metamorfosis de Ovidio da forma literaria a una crisis de la experiencia: el fin de la República y el pasaje a una nueva forma de gobierno, el Principado. Tomaremos como marco teórico el concepto de "estructura del sentir" de Raymond Williams que se define como la expresión de la interacción entre el "carácter social dominante de un período" y la "experiencia real". Nosotros postulamos que el episodio de Cipo señala un conflicto entre una idea dominante, la visión negativa de la figura del rey, y un nuevo sentimiento, la posibilidad de un rey con virtus.

Palabras clave: Metamorfosis - Cipo- estructura del sentir - monarquía

\begin{abstract}
:
Our purpose in this paper is to analyse how the Cipus episode in Ovid's Metamorphoses XV gives a literary shape to a crisis of experience: the end of the Republic and the transition to a new form of government, the Principate. We will take as a theoretical framework Raymond Williams's concept of "structure of feeling", which is defined as the expression of the interaction between the dominant social character of a period and actual experience. We postulate that the Cipus episode points to a conflict between a dominant idea, the negative view over the king's figure, and a new feeling, the possibility of a virtuous king.
\end{abstract}

Keywords: Metamorphoses - Cipus - structure of feeling - monarchy

RECIBIDO: 28-6-2017 - ACEPTADO: 17-10-2017 